\title{
A PRODUÇÃO DE DOCUMENTÁRIOS AMBIENTAIS SOBRE O PARQUE NACIONAL DA TIJUCA PARA VALORIZAÇÃO E PRESERVAÇÃO DA MATA ATLÂNTICA
}

\section{PRODUCTION OF DOCUMENTARIES ON TIJUCA NATIONAL PARK FOR ENHANCEMENT AND PRESERVATION OF THE ATLANTIC FOREST}

\author{
QUEIROZ, Amanda Pimentel Berkde ${ }^{1}$ \\ ROCHA, Marcelo Borges ${ }^{2}$ \\ MATTA, Roberta da ${ }^{3}$ \\ RAMOS, Alexander ${ }^{4}$ \\ QUEYROI, Luisa Coutinho ${ }^{55}$
}

\section{RESUMO}

As unidades de conservação (UC) apresentam potencial educativo principalmente por proporcionar um aprender vinculado ao cotidiano. Produções e disseminações de vídeos possibilitam atingir um grande número de cidadãos. Esse foi um trabalho descritivo a respeito do projeto Conexão Ambiental/CEFET-RJ, desenvolvido por docentes e discentes do Programa de Pós-graduação em Ciência, Tecnologia e Educação, que consiste na produção de documentários ambientais com 0 intuito de divulgação científica sobre locais de reconhecida relevância ambiental. Foram produzidos dois curtas-metragens, com aspectos históricos e de biodiversidade do Parque Nacional da Tijuca, uma UC de Mata Atlântica. Observa-se que o uso do documentário ambiental mobiliza os indivíduos para uma aproximação e sensibilização sobre o espaço retratado.

PalaVras-ChaVe: Documentários; Educomunicação; Mata Atlântica; Unidades de Conservação

\section{ABSTRACT}

Conservation units (UC) have educational potential mainly by providing learning associated to everyday life. Production and dissemination of videos make it possible to reach a large

\footnotetext{
${ }^{1}$ Mestre em Engenharia Ambiental, Graduada em Ciências Biológicas pela Faculdade de Formação de Professores da UERJ, pesquisadora da área de Meio Ambiente e Educação Ambiental. e-mail: berk.amanda@yahoo.com.br

${ }^{2}$ Professor da Graduação e de Pós-Graduação do CEFET-RJ. e-mail: rochamarcelo36@yahoo.com.br

${ }^{3}$ Graduada em Ciências Biológicas pela UERJ. Especialista em Educação Básica, modalidade Ensino de Biologia, pela UERJ. Mestre em Ciência, Tecnologia e Sociedade pelo CEFET/RJ. Professora efetiva na Prefeitura Municipal de Itaguaí/RJ. e-mail: beta_matta@hotmail.com

${ }^{4}$ Graduando do curso de gestão ambiental no CEFET/RJ. e-mail: alex_ander@hotmail.com.br

${ }^{5}$ Graduanda e estagiária no CEFET-RJ. e-mail: luisa-queyroi@hotmail.com
} 
DOI: $10.12957 /$ e-mosaicos.2018.32103

number of citizens. This descriptive paper addresses the project "Environmental Connection"/CEFET-RJ, developed by teachers and students of the Graduate Program in Science, Technology and Education. The project produces documentaries on places with recognized environmental relevance. Two short films were produced on historical aspects and biodiversity of Tijuca National Park, an Atlantic Forest conservation unit. It was observed that the use of environmental documentary film mobilizes individuals to reach out to and become aware of that specific area.

KEY-WORDS: Documentaries; Educational Communication; Forest; Conservation Units.

\section{INTRODUÇÃo}

As unidades de conservação da natureza (UC) são áreas protegidas segundo a Lei Federal no 9.985/2000 que instituiu o Sistema Nacional de Unidades de Conservação da Natureza (SNUC). Nesse documento as UCs foram definidas como:

Espaço territorial e seus recursos ambientais, incluindo as águas jurisdicionais, com características naturais relevantes, legalmente instituído pelo Poder Público, com objetivos de conservação e limites definidos, sob regime especial de administração, ao qual se aplicam garantias adequadas de proteção (BRASIL, 2000, p. 1).

São estabelecidas unidades nas esperas federais, estaduais e municipais, divididas em dois tipos: Proteção Integral e Uso Sustentável. As Unidades de Proteção Integral objetivam a preservação da natureza, sendo admitido apenas o uso indireto dos seus recursos naturais, com exceção dos casos previstos na Lei. Já as Unidades de Uso Sustentável priorizam compatibilizar a conservação da natureza com o uso sustentável de parcela dos seus recursos naturais (BRASIL, 2000).

Alguns dos principais objetivos do SNUC são "contribuir para a manutenção da diversidade biológica e dos recursos genéticos no território nacional e nas águas jurisdicionais; proteger as espécies ameaçadas de extinção no âmbito regional e nacional; contribuir para a preservação e a restauração da diversidade de ecossistemas naturais; promover o desenvolvimento sustentável a partir dos recursos naturais" (BRASIL, 2000, p. 2).

As UCs estão inseridas no grupo dos espaços não formais de ensino, desempenhando papel relevante principalmente por proporcionar um aprender vinculado ao cotidiano e permitir uma integração do saber científico à realidade sócio-cultural dos educandos (MEYER, 2000). O desempenho desses papéis fica claro nos objetivos previstos no SNUC, anteriormente citados.

Ainda que seja reconhecida a sua importância para o ensino, estas áreas têm sido pouco exploradas pelos educadores, principalmente, no que diz respeito ao desenvolvimento de atividades de Educação Ambiental e conservação (CERATI E LAZARINI, 2009). Esse fato justifica a proposta de práticas que possam aproximar as UCs do público, principalmente o escolar. 


\section{Breve Histórico do Parque Nacional da Tijuca}

A região onde hoje é o Parque Nacional da Tijuca (PNT) já era reconhecida e havia relatos de usufruto recreativo e de vislumbre muito antes da área ser uma Unidade de Conservação da Natureza (UC). Nos séculos XVII e XVIII, o Maciço da Tijuca foi, em sua maior parte, ocupado e devastado pela extração de madeiras e da utilização em monoculturas, especialmente o café, o que gerou sérios problemas ambientais com efeitos na cidade do Rio de Janeiro, principalmente com relação à escassez de água (PARQUE NACIONAL DA TIJUCA, 2016).

Em 1861, as florestas da Tijuca e das Paineiras foram declaradas por D. Pedro II como Florestas Protetoras e teve início então um processo de desapropriação de chácaras e fazendas, com o objetivo de promover 0 reflorestamento e permitir a regeneração natural da vegetação, confiado inicialmente ao Major Manuel Gomes Archer. Em apenas 13 anos, mais de 100 mil árvores foram plantadas, principalmente espécies da Mata Atlântica. O plantio teve continuidade nos anos seguintes e, associado ao processo de regeneração natural, formou a grande floresta existente hoje no Maciço da Tijuca (PARQUE NACIONAL DA TIJUCA, 2016).

O feito histórico do reflorestamento das serras da Tijuca ganhou fama internacional e durante muito tempo foi considerada a maior floresta urbana do mundo, título que chama atenção por conta de uma aparente contradição na coexistência floresta-cidade. Na verdade, os principais argumentos que estimularam sua criação no século XIX foram as demandas urbanas de abastecimento de água, de produção de um clima saudável e de áreas de lazer para a elite carioca. A imagem de um grande jardim, paisagisticamente planejado no meio de uma grande cidade, incorporou aos poucos as representações trazidas pelos ideários conservacionistas de uma natureza intocada e que deveria ser preservada desse modo, quando foi transformado, em 1961, junto com as demais florestas que compõem seu maciço, em parque nacional (FERNANDEZ, 2011).

Após anos de relativo abandono e esforços pontuais de manutenção, a Floresta da Tijuca teve um período de forte revitalização na gestão do milionário e mecenas Raymundo Ottoni de Castro Maya, na década de 1940. A revitalização incluiu a abertura dos Restaurantes Esquilos, Floresta e Cascatinha, a consolidação das vias internas e os recantos e projetos paisagísticos de Roberto Burle Marx (PARQUE NACIONAL DA TIJUCA, 2016).

Em 1961, o Maciço da Tijuca - Paineiras, Corcovado, Tijuca, Gávea Pequena, Trapicheiro, Andaraí, Três Rios e Covanca - foi transformado em Parque Nacional, recebendo o nome de Parque Nacional do Rio de Janeiro, com $33 \mathrm{~km}^{2}$. Seis anos depois, em 8 de fevereiro de 1967, seu nome foi definitivamente alterado para Parque Nacional da Tijuca e, em 4 de julho de 2004, um Decreto Federal ampliou os limites do Parque para 39,51 km², incorporando locais como o Parque Lage, Serra dos Pretos Forros e Morro da Covanca (PARQUE NACIONAL DA TIJUCA, 2016). 
e-Mosaicos - Revista Multidisciplinar de Ensino, Pesquisa, Extensão e Cultura do Instituto de Aplicação Fernando Rodrigues da Silveira (CAp-UERJ)

V. 7 - N. 15 - AGOSTO 2018 - ISSN: 2316-9303

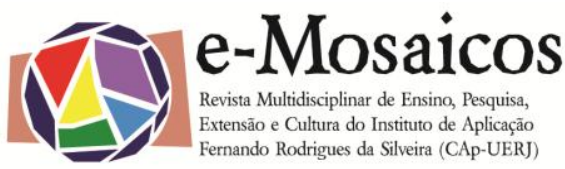

DOI: $10.12957 / \mathrm{e}-\mathrm{mosaicos} .2018 .32103$

Atualmente, o PNT é composto por três setores que podemos citar respectivamente: a Serra dos Três Rios, também conhecida por de Floresta da Tijuca, destacando o Pico da Tijuca, com 1.021m de altitude; a Serra da Carioca, abrangendo o Morro do Sumaré e o Pico do Corcovado, com 732m de altitude e uma área de encostas íngremes, contendo a Pedra da Gávea e a Pedra Bonita, com 842m e $696 \mathrm{~m}$ de altitude. Os três setores do Parque localizam-se na região denominada Maciço da Tijuca (DE FREITAS; MAGALHÃES; GUAPYASSÚ, 2002). Os cumes pertencentes ao Parque são referência turística e são amplamente utilizados pelos moradores e visitantes como áreas de lazer e de contemplação.

Sua gestão é feita pelo órgão ambiental federal Instituto Chico Mendes de Conservação da Biodiversidade (ICMBio) e conta com uma equipe de guias que acompanham grupos agendados, uma administração, alguns especialistas técnicos, seguranças e um programa de voluntariado que colabora com sua manutenção.

Por estar situado no meio da área urbana, o parque oferece importantes serviços ambientais à cidade, auxiliando na regulação do equilíbrio hídrico, no controle de erosão de encostas, na prevenção contra o assoreamento dos cursos d'água, na conservação da qualidade do solo e na regulação do clima do Estado do Rio de Janeiro (ICMBIO, 2016).

\section{EdUCOMUNICAÇÃo SOCIOAMBIENTAL}

Cada vez mais a população tem mostrado interesse por questões relacionadas ao meio ambiente. Tais questões envolvem a preocupação com o que já foi feito, o que se pode fazer para evitar os problemas ambientais e qual o papel de cada cidadão no sentido de minimizar os efeitos dos impactos ambientais sentidos na atualidade. Muitas escolas abordam essas questões através de diversos tipos de ações, entre estas, as de educomunicação, utilizando-se de meios como televisão, rádio, jornal, documentários e fotografias.

A educomunicação socioambiental pode ser entendida como as ações educativas no campo da comunicação ambiental. Esta área passa a ser adotada como uma política pública a partir da necessidade do Departamento de Educação Ambiental do Ministério do Meio Ambiente (DEA/MMA), em 2005. Com proposta de formular metodologias de produção e veiculação dos conteúdos de educação ambiental pelos meios de comunicação, esta política de comunicação ambiental também é considerada uma cultura educativa. Vieira e Rosso (2011) argumentam que o uso educativo de vídeos permite na educação ambiental um patamar de incorporação de valores para promover a mudança de atitudes frente ao meio ambiente.

A educomunicação socioambiental pode ser percebida como uma ferramenta propulsora de informação e conhecimento. Parte-se do pressuposto que, com produções de vídeos, jornais e campanhas midiáticas trabalhadas em escolas, tornase possível atingir um grande número de cidadãos. Serra e Arroio (2009) afirmam que há o estabelecimento de uma interação entre o indivíduo e seu meio a partir da 


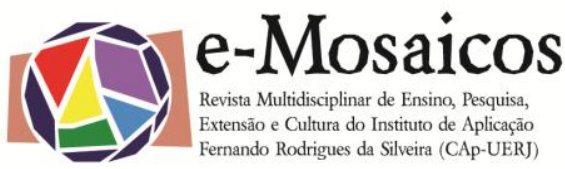

DOI: $10.12957 /$ e-mosaicos.2018.32103

utilização de recursos audiovisuais como ferramenta pedagógica e de disseminação da informação. Sendo assim, essas produções podem ser consideradas como divulgação científica.

Assim delimitamos como objetivo deste trabalho articular os pressupostos da educomunicação a temática socioambiental através da produção de materiais, nesse caso documentários, a respeito de uma UC de Mata Atlântica de grande proeminência no país, o Parque Nacional da Tijuca.

\section{Metodologia}

\section{Conhecendo o Projeto Conexão Ambiental}

O projeto Conexão Ambiental é desenvolvido pelo Laboratório de Divulgação Científica e Ensino de Ciências (LABDEC) localizado no Centro Federal de Educação Tecnológica Celso Suckow da Fonseca (CEFET-RJ) e conta com apoio financeiro de bolsas fomentadas pela Capes a alunos de graduação do curso de Gestão Ambiental da instituição (CEFET-RJ) e pós-graduação vinculados ao Programa de Pósgraduação em Ciência, Tecnologia e Educação (PPCTE) da mesma unidade de ensino, sob a coordenação do professor Dr. Marcelo Rocha.

O projeto consiste na produção de documentários ambientais com o intuito de divulgação científica sobre locais de reconhecida relevância ambiental e significativo papel de contribuição para a qualidade de vida da população, assim como a utilização desses produtos como material didático em diferentes esferas para colaborar com a sensibilização ambiental.

O projeto conta com o auxílio de funcionários técnicos da TV CEFET, departamento que possui um acervo específico com equipamentos eletrônicos profissionais para as etapas de gravação e edição. Em 2015, um dos alvos recentes de investigação foi a temática a respeito da Baía de Guanabara, onde foram produzidos quatro documentários sobre este tema, culminando num evento de lançamento da coletânea.

Todas as etapas desde a idealização e concepção dos temas, elaboração dos roteiros, reconhecimento das áreas de estudo, captura de imagens, edições e finalizações são realizadas inteiramente pelos alunos do projeto e equipe técnica. Oliveira (2012) aponta a importância e a contribuição para esse tipo de atividade na formação do estudante e indica que deva haver grande ênfase nesse aspecto em projetos semelhantes como o que apresentamos aqui.

Os estudantes do PPCTE exercitam a aplicação de seus conhecimentos acerca da articulação de temas como o ensino e a tecnologia através do projeto, assim como buscam mecanismos de colaborar com a melhoria de estratégias de divulgação científica e do ensino de ciências.

Dessa forma há uma valiosa interação entre os alunos do PPCTE e os graduandos que podem observar e aprenderem juntos numa experiência cooperativa 
e-Mosaicos - Revista Multidisciplinar de Ensino, Pesquisa, Extensão e Cultura do Instituto de Aplicação Fernando Rodrigues da Silveira (CAp-UERJ)

V. 7 - N. 15 - AGOSTO 2018 - ISSN: 2316-9303

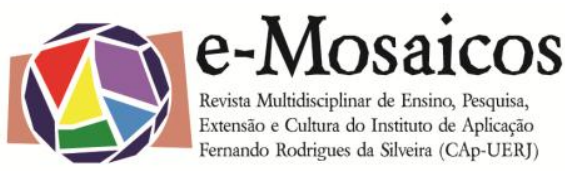

DOI: $10.12957 /$ e-mosaicos.2018.32103

e participativa coletiva. Cardoso e Teixeira (2013) apontam que a produção de documentários pelos alunos possibilita uma interação positiva entre os mesmos, uma visão mais holística sobre o ambiente tornando os educandos atores da aprendizagem e construtores do conhecimento.

O diferencial da nossa proposta em relação às demais vistas na literatura é a participação de alunos de graduação e pós-graduação nessas etapas de desenvolvimento dos documentários. Esse fator indica além da sensibilização dos indivíduos, como é exposto em trabalhos como os de Cardoso e Teixeira (2013) e De Abreu (2008), uma capacitação mais direcionada para o quesito profissional devido à etapa mais avançada de formação desses educandos. Sendo assim, os mesmos após essa experiência, tornam-se agentes de divulgação e de transformação em suas futuras atuações.

\section{Produção de documentários sobre o Parque Nacional da Tijuca}

A área de estudo selecionada para a nova coletânea de documentários foi o Parque Nacional da Tijuca, na figura 1 pode-se observar a beleza cênica do local. A escolha foi feita por se tratar de uma unidade localizada em uma grande metrópole, de fácil acesso, com potencial educativo, contando com exposições interativas. 0 parque possui grande área de abrangência no município do Rio de Janeiro e múltipla importância para a cidade como a regulação do clima, habitat de inúmeras espécies, berço ecológico de ecossistemas variados e espaço de conservação de grande parte da Mata Atlântica remanescente.

Figura 1: Vista de um dos pontos do Parque Nacional da Tijuca

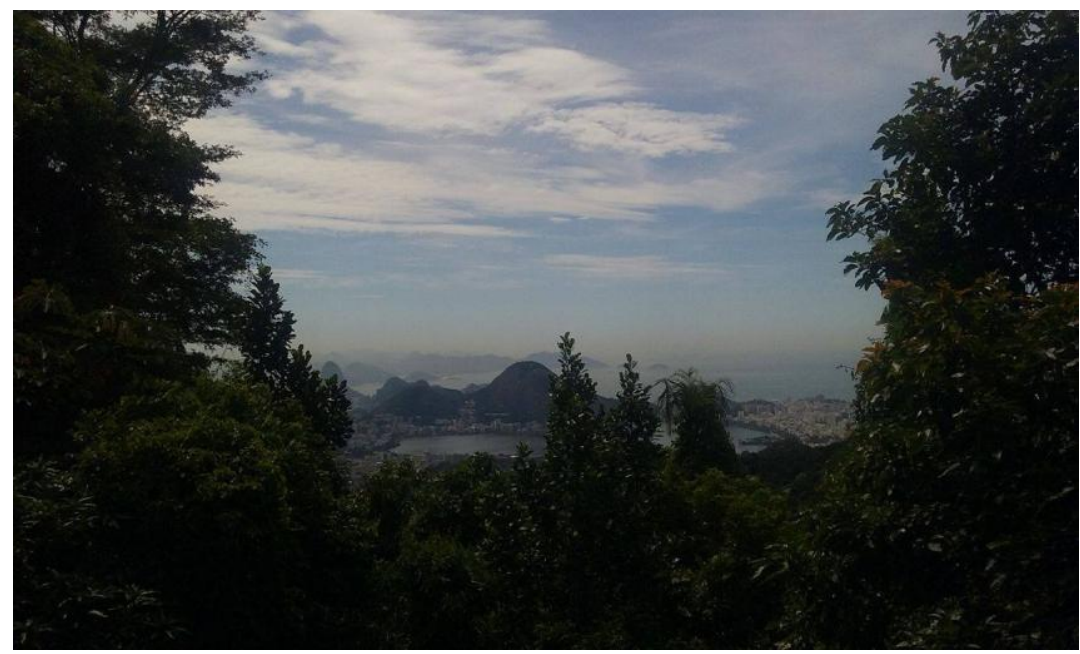

Fonte: Pessoal.

O PNT é constituído por um relevante fragmento de Mata Atlântica em avançado estágio de regeneração no estado do Rio de Janeiro, com uma área total de 3.953 ha, equivalente à cerca de 3,5\% da área do município do Rio de Janeiro. 
DOI: $10.12957 /$ e-mosaicos.2018.32103

Apresenta diversidade de flora e fauna, belezas naturais como cachoeiras e grutas, além de obras arquitetônicas de grande valor histórico e artístico, e trilhas com representações de outros animais além dos da Mata Atlântica.

A proposta dessa pesquisa se enquadra numa pesquisa qualitativa, teóricoempírica, realizada através de observações dos pesquisadores durante a produção e as saídas de campo, realizadas para a coleta de dados, nesse caso imagens e entrevistas.

A abordagem utilizada apresenta características descritivas, dessa forma enquadrando a presente pesquisa na abordagem qualitativa definida como pesquisa etnográfica (LÜDKE E ANDRÉ, 2012).

\section{RESULTADOS E DISCUSSÕES}

Foram realizadas diferentes atividades para viabilizar a produção dos documentários ambientais do Parque Nacional da Tijuca. As atividades foram desenvolvidas no segundo semestre de 2015 e primeiro de 2016.

Como produto final foram gerados dois documentários, curta metragens com cerca de 10 minutos de duração cada, contendo: imagens capturadas pela equipe, entrevistas com especialistas e relatos de frequentadores, narrações com informações sobre ambos os temas de abordagem - a Biodiversidade e o Histórico da unidade de conservação em questão.

De Abreu (2008) expõe um trabalho de produção de material multimídia defendendo essa prática como uma estratégia de divulgação de informações e mobilização acerca da relação do homem com áreas protegidas e seu uso adequado a fim de mitigar os impactos negativos e a degradação ambiental. Dessa maneira o trabalho da autora se equipara ao presente estudo que utiliza metodologia semelhante para alcançar esse objetivo.

A propagação dos documentários produzidos neste trabalho almeja contribuir para a qualidade de vida da população do Rio de Janeiro, uma vez que enaltecem e valorizam a Mata Atlântica. Dessa maneira incentivam a frequência dos habitantes a esse espaço natural e busca sensibilizar através da divulgação de suas informações e características. Influenciando possivelmente também na qualidade ambiental da região uma vez que os visitantes tenham um novo olhar para a importância da preservação local.

\section{Etapa 1: Elaboração dos roteiros}

$\mathrm{Na}$ fase de pré-produção para a realização dos documentários foram elaborados roteiros durante as reuniões semanais do grupo. Os roteiros foram utilizados como guias para a captura das imagens. 
DOI: $10.12957 /$ e-mosaicos.2018.32103

Inicialmente a equipe se reuniu para a definição de questões como o tema, a área de estudo, os textos a serem inseridos na narração, as perguntas a serem feitas aos entrevistados, os pontos de filmagem que seriam escolhidos, entre outras questões como o cronograma e etapas seguintes de trabalho.

Uma pesquisa bibliográfica extensa foi realizada para que houvesse um conhecimento da equipe sobre as questões como unidades de Conservação, a Mata Atlântica, espécies de fauna e flora, aspectos com potencial educativo e características mais importantes do PNT.

Após as reuniões iniciais, a equipe realizou visitas técnicas para legitimar as escolhas de pontos de filmagem e a disponibilidade de entrevistados, como os funcionários do parque, assim como a percepção dos indivíduos mais adequados para relatar as informações desejadas sobre o local.

\section{Etapa 2: captura de imagens}

A captura de imagens, que constitui a fase de produção, foi realizada em três visitas realizadas no Parque Nacional da Tijuca (PNT), com auxílio e entrevistas de representantes do parque previamente contatados e outros quatro dias de filmagens externas em locais combinados e convenientes aos especialistas entrevistados. A tabela 1 apresenta a execução da etapa de gravações.

Tabela1: Cronograma de execução de atividades de captura de imagens para os documentários

\begin{tabular}{c|c}
\hline $\begin{array}{c}07 \text { de novembro de } \\
2015\end{array}$ & $\begin{array}{c}\text { Saída ao parque para seleção de locais de } \\
\text { gravação pertinentes }\end{array}$ \\
\hline $\begin{array}{c}\text { Captação de imagens no PNT } \\
2015\end{array}$ & $\begin{array}{c}\text { Entrevista com Peterson de Almeida } \\
\text { (funcionário) } \\
\text { Entrevista com Alberto Dias Salgado } \\
\text { (funcionário) }\end{array}$ \\
\hline $\begin{array}{c}19 \text { de novembro de } \\
2015\end{array}$ & Entrevista com Ana Maria Donato (UERJ) \\
\hline 08 de dezembro de & Entrevista com Douglas Pimentel (UFF) \\
\hline 02 de fevereiro de & Captação de imagens no PNT \\
2016 & Entrevista com visitantes \\
\hline 26 de fevereiro de & $\begin{array}{c}\text { Captação de imagens no PNT (vista chinesa, } \\
\text { mesa do imperador) e no Jardim Botânico } \\
\text { Entrevista com frequentadores }\end{array}$ \\
\hline 01 de março de 2016 & Entrevista com Jorge Pontes (Prefeitura) \\
\hline 21 de março de 2016 & Entrevista com José Augusto Pádua (Gávea) \\
\hline
\end{tabular}


DOI: $10.12957 /$ e-mosaicos.2018.32103

A seleção das cenas foi realizada em busca de privilegiar aspectos diversos da unidade de conservação, com destaque para as áreas de história e biodiversidade. Privilegiamos temas como seu processo de criação, a importância da preservação do ecossistema para a localidade, sua relação com a comunidade, sua biodiversidade e condições e cotidiano de sua manutenção. A lista a seguir sumariza os pontos adotados no setor Floresta dentro da Floresta da Tijuca e outros pontos. $\mathrm{Na}$ figura 2 demonstra-se momento das gravações e captura em um dos pontos de filmagem ao longo dos cronogramas previstos pela equipe.

\section{PARADAS PARA AS GRAVAÇões doS doCUMENTÁRIOS NO SETOR FLORESTA:}

1- Cascatinha;

2- Centro dos visitantes;

3- O playground;

4- Na escada (vista panorâmica);

5- Lago atrás do centro dos visitantes;

6- Barracão;

7- Capela;

8- Restaurantes "Os Esquilos" e "A Floresta";

9- A placa P08 (roteiro da biodiversidade);

10-A placa P09 (roteiro histórico).

Figura 2: Filmagem da mesa do Imperador dentro da Floresta da Tijuca.

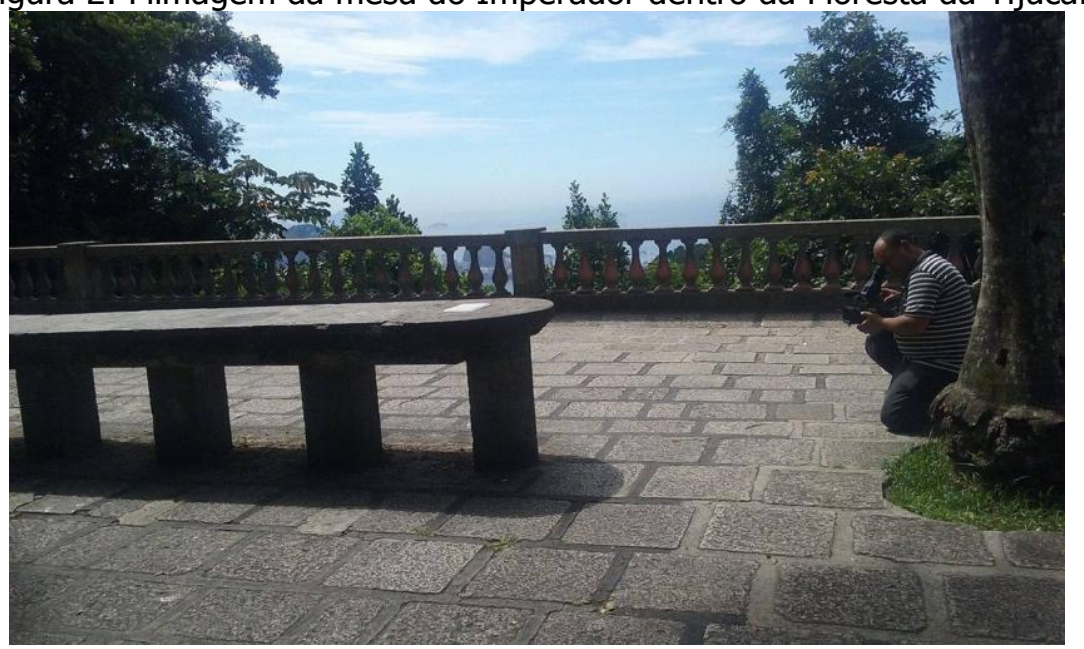

Fonte: Pessoal.

\section{FILMAGENS EXTERNAS:}

1- Jardim Botânico;

2- Vista Chinesa.

A escolha dos lugares, por privilegiar as imagens paisagísticas, justifica-se pelo apelo cênico que acaba por atrair o público. Cabe ainda ressaltar que, tratandose de um assunto da temática ambiental, as imagens em ambientes naturais 
e-Mosaicos - Revista Multidisciplinar de Ensino, Pesquisa, Extensão e Cultura do Instituto de Aplicação Fernando Rodrigues da Silveira (CAp-UERJ)

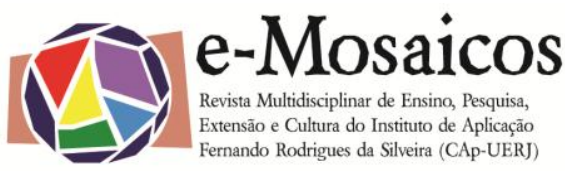

DOI: $10.12957 /$ e-mosaicos.2018.32103

despertam o interesse do telespectador, como descrito anteriormente por nosso grupo em relação à preferência por lugares e pessoas (MATTA et al, 2014).

No que tange ao papel desempenhado pelas pessoas em um vídeo, optamos pela inclusão das entrevistas com especialistas, pois já foi descrito em trabalhos anteriores que o público sente-se atraído por esse tipo de atividade (MATTA et al, 2014). Há também uma maior credibilidade na fala de indivíduos que tenham formação direcionada e conhecimento de causa para tratar dos conceitos e informações pertinentes aos temas escolhidos no roteiro (SANTOS, 2011).

Dessa forma realizamos uma busca de especialistas em temas afins tratados nos roteiros e verificamos a disponibilidade dos mesmos para a participação na obra. $\mathrm{Na}$ figura 3 observa-se entrevista com um dos especialistas que contribuíram para essa vertente dos documentários.

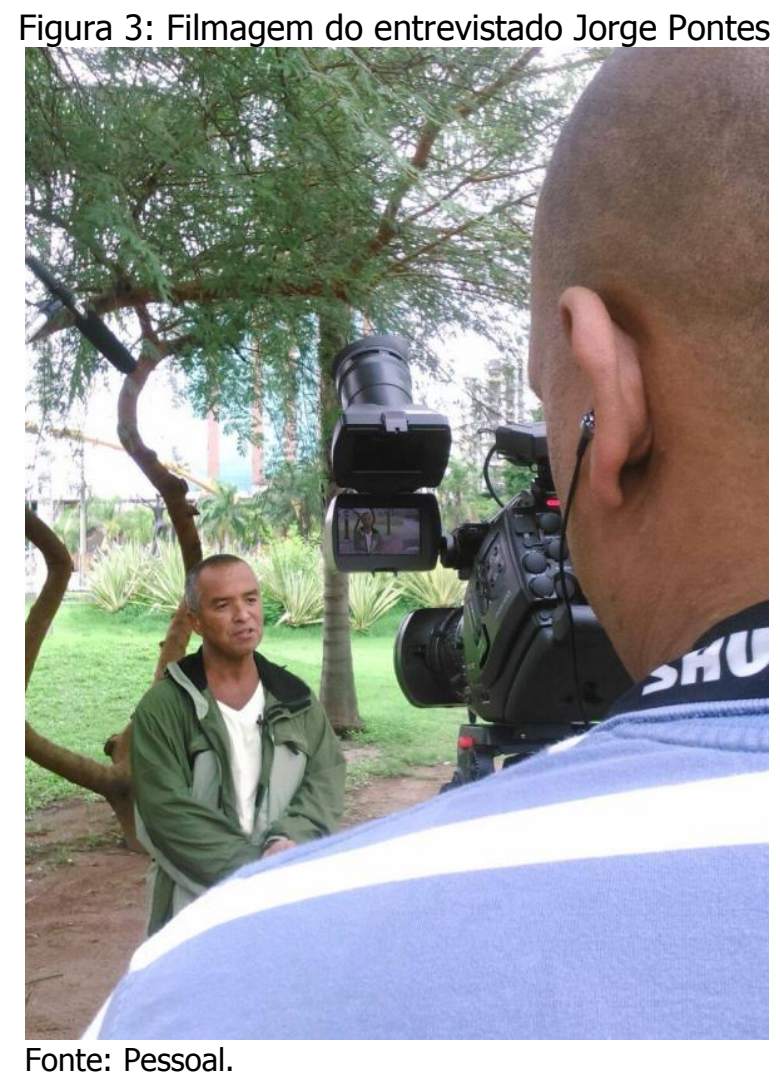

\section{Etapa 3: Edição}

As fases de produção e pós-produção foram realizadas utilizando recursos e suporte técnico da TV CEFET. O programa utilizado para a edição foi o Adobe Premiere. Nesse ponto são incluídos itens como as legendas, as músicas de fundo, entre outros elementos de finalização que compõe o formato pretendido e torna o produto mais agradável e dinâmico para ser exibido ao público. 
DOI: $10.12957 /$ e-mosaicos.2018.32103

Nesse momento foi realizada a decupagem seletiva escolhendo as imagens captadas que revelassem melhor o que se predispunha no roteiro e sincronizando como pano de fundo para as falas dos entrevistados. Outro aspecto importante na escolha de cenas foi exaltar a beleza exuberante que propicia a valorização do espaço exposto aos indivíduos aguçando a curiosidade dos mesmos para que desejem visitar e colaborar com a preservação do mesmo durante sua visitação.

Essa divulgação é também um dos objetivos do projeto que busca através da sensibilização estimular o contato dos cidadãos com espaço naturais e a compreensão da magnitude de relações ecológicas que o mesmo abriga. Segundo Cerati e Lazarini (2009) esse apelo à consciência crítica de grupos sociais circundantes é considerado uma ação efetiva para a proteção desses locais naturais.

\section{CONSIDERAÇõES FINAIS}

Nos últimos anos o desenvolvimento das novas tecnologias da comunicação, bem como o seu uso no ambiente escolar tem fornecido reais possibilidades de aumentar a interação dos alunos com o conhecimento científico. Além disso, esses recursos proporcionam uma maior sensibilização, sobretudo das questões ambientais, favorecendo uma aprendizagem mais dinâmica e ativa por parte dos alunos.

Sendo assim, a produção e o uso de documentários com enfoque na Educação Ambiental representam um avanço, uma vez que através dos vídeos, os telespectadores terão conhecimento dos ambientes naturais e dos seus problemas intrínsecos. Desta forma, por meio de atividades educativas poder-se-á contribuir para a formação de pessoas mais conscientes acerca da importância de se preservar o meio ambiente.

Observa-se que o uso do documentário ambiental como instrumento sensibilizador permite a aproximação da realidade, de situações e lugares que parecem distantes e pela constituição de um importante recurso imagético.

\section{REFERÊNCIAS}

BRASIL. Sistema Nacional de Unidades de Conservação. Lei no 9.985, de 18 de julho de 2000.

CARDOSO, L. de R.; TEIXEIRA, T. A. Documentário ambiental: notas sobre uma produção com educandos. In: Ambiente \& Educação, v. 18, n. 1, PP. 59-77, 2013.

CERATI, T. M.; LAZARINI, R. A. M. A pesquisa-ação em educação ambiental: uma experiência no entorno de uma unidade de conservação urbana. In: Ciência \& Educação, v. 15, n. 2, p. 383-92, 2009. 
DOI: $10.12957 /$ e-mosaicos.2018.32103

DE ABREU, P. C. Produção multimídia de Educação Ambiental como ferramenta da gestão participativa de áreas protegidas. Circuito de Iniciação Científica, 2008.

DE FREITAS, W. K.; MAGALHÃES, L. M. S.; GUAPYASSÚ, M. dos S. Potencial de uso público do Parque Nacional da Tijuca. Acta Scientiarum. Technology, v. 24, p. 1833$1842,2008$.

FERNANDEZ, A. C. F. Um Rio de florestas: uma reflexão sobre o sentido da criação dos parques na cidade do Rio de Janeiro. In: Estud. hist. (Rio J.), v. 24, n. 47, p. 141-161, 2011.

ICMBIO. Parque Nacional de Tijuca. "Disponível em:

$<$ http://www.icmbio.gov.br/portal/o-que-fazemos/visitacao/unidades-abertas-avisitacao/210-parque-nacional-da-tijuca.html>. Acesso em 15 de mar. de 2016."

LÜDKE, M.; ANDRÉ, M. E. D. A. Pesquisa em educação: abordagens qualitativas. São Paulo. 2012.

MATTA, R. R.; ROCHA, M. B.; CARVALHO, I. L. A. Análise da percepção de estudantes do ensino fundamental a respeito do uso de documentários ambientais na sala de aula. In: Anais do Simpósio sobre divulgação cientifica na sala de aula: perspectivas e possibilidades, p. 51-54. São Paulo, 2014.

MEYER, M. A. A. Além das quatro paredes. In: Coletânea do 70 Encontro Perspectivas do Ensino de Biologia, São Paulo. p. 849, 2000.

OLIVEIRA, H. L. P. Documentários e animações produzidos no LAPIS para uso na Educação Básica. In: EntreVer - Revista das Licenciaturas, v. 2, n. 2, p. 326-344, 2012.

PARQUE NACIONAL DA TIJUCA. História. "Disponível em: <http://www.parquedatijuca.com.br/\#historia>. Acesso em 15 de mar. de 2016."

SANTOS, S. P. Fatores de sucesso da comunicação da informação ambiental segundo especialistas. 2011. 160 p. Tese (Doutorado em Ciência da Informação)-Universidade de Brasília, Departamento de Ciência da Informação e Documentação, 2011.

SERRA, G.; ARROIO, A. O meio ambiente apresentado em filmes de ficcão e documentários. In: Enseñanza de las Ciencias, Número Extra VIII Congreso Internacional sobre Investigación em Didáctica de las Ciencias, Barcelona, 2009. pp. 2797-2802

VIEIRA, F. Z.; ROSSO, A. J. O cinema como componente didático da educação ambiental. In: Revista Diálogo Educacional, v. 11, n. 33, p. 547-572, 2011. 